\title{
LETTER
}

\section{Letter to the Editor Regarding: "Agreement Between Trend-Based and Qualitative Analysis of the Retinal Nerve Fiber Layer Thickness for Glaucoma Progression on Spectral-Domain Optical Coherence Tomography"}

Young Hoon Hwang (D)

Received: October 4, 2021 / Accepted: November 23, 2021 / Published online: December 6, 2021

(c) The Author(s) 2021

Dear Editor,

I read with great interest the article by Thompson et al. [1], regarding the detection of glaucoma progression by optical coherence tomography (OCT) retinal nerve fiber layer (RNFL) thickness analysis. The results of this study revealed that the presence of artifacts affected progression detection. As an example, the authors presented a case (Fig. 2) with an epiretinal membrane around the optic nerve head. In the figure legends, the authors commented: "However, the raw optical coherence tomography B-scans in the upper right panels demonstrate that this change is due to a decrease in traction from the epiretinal membrane, and is thus an example of false progression." I agree that this change is a false progression. I would like to suggest another possible cause of this phenomenon. In the fundus image, a prominent RNFL with thick striae around the optic nerve head is visible, and splitting of the RNFL with the presence of schisis cavities within the RNFL is found on the OCT B-scan images. These findings can be observed in conditions with peripapillary retinoschisis [2]. If the RNFL margins automatically identified by the OCT algorithm include the schisis cavity, it may cause RNFL thickening (Fig. 1) [2]. In the case presented in Fig. 2, RNFL thickening was observed in the first test (schisis cavity between the anterior and posterior RNFL borders), and the inner border of RNFL (red curved line) did not include the schisis cavity for the segmentation of RNFL in the most recent test. This change may be another cause of false RNFL thinning in this case. 


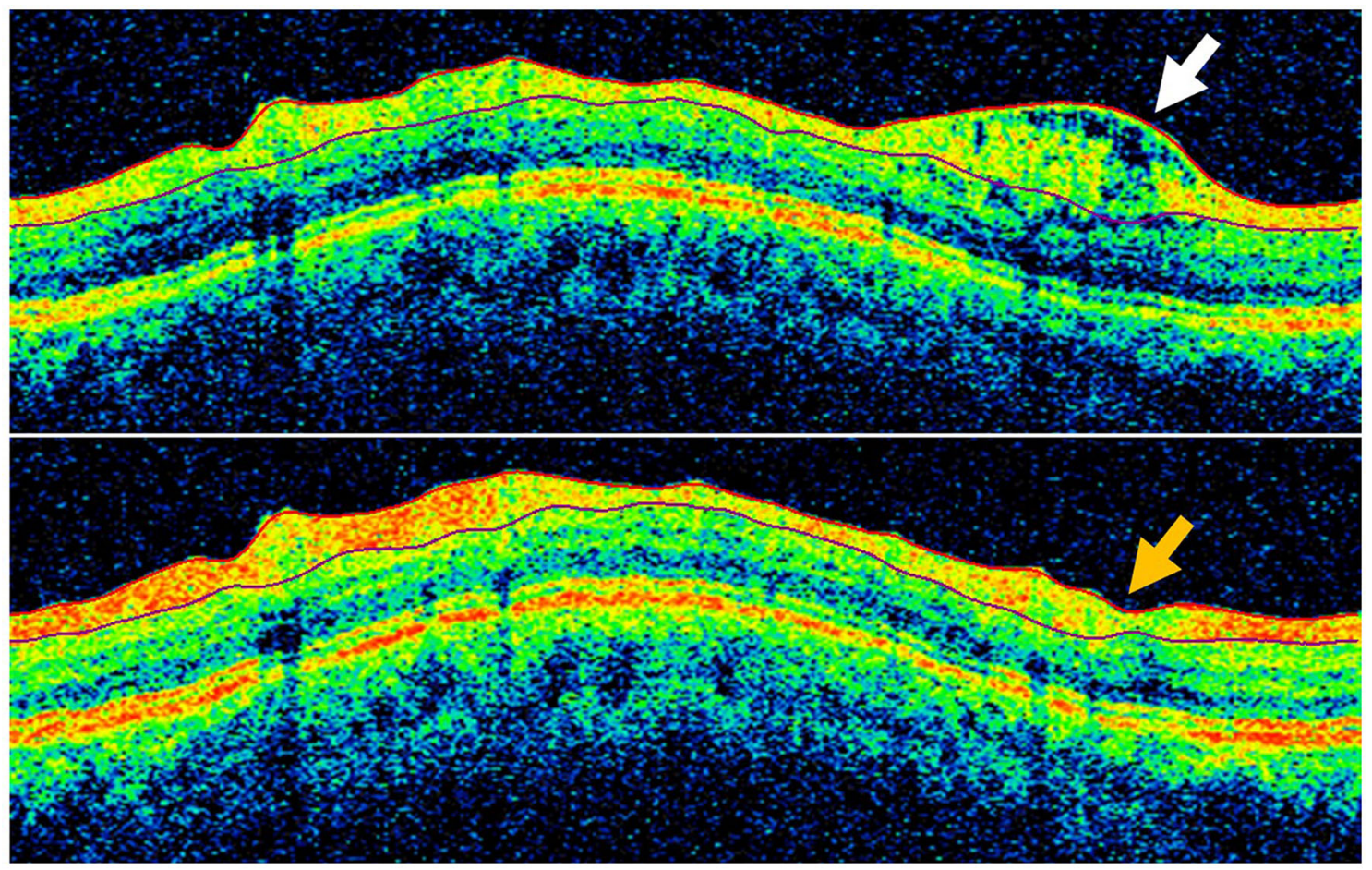

Fig. 1 Cross-sectional retinal images obtained by optical coherence tomography (OCT) in a glaucomatous eye with peripapillary retinoschisis. When retinoschisis was present (top, white arrow), it was associated with a transient

\section{ACKNOWLEDGEMENTS}

Funding. No funding or sponsorship was received for this study or publication of this article.

Authorship. The named author meets the International Committee of Medical Journal Editors (ICMJE) criteria for authorship for this article, takes responsibility for the integrity of the work as a whole, and has given their approval for this version to be published.

Author Contributions. Concept and design (YHH), drafting the manuscript (YHH), review and approval of the final version (YHH). increase in retinal nerve fiber layer thickness. Disappearance of retinoschisis (bottom, yellow arrow) induced a decrease in retinal nerve fiber layer thickness

Disclosures. Young Hoon Hwang has no personal, financial, commercial, or academic conflicts of interest to declare.

Compliance with Ethics Guidelines. This article is based on previously conducted studies and does not contain any new studies with human participants or animals performed by the author.

Data Availability. Data sharing is not applicable to this article as no datasets were generated or analyzed during the current study.

Open Access. This article is licensed under a Creative Commons Attribution-NonCommercial 4.0 International License, which permits any non-commercial use, sharing, 
adaptation, distribution and reproduction in any medium or format, as long as you give appropriate credit to the original author(s) and the source, provide a link to the Creative Commons licence, and indicate if changes were made. The images or other third party material in this article are included in the article's Creative Commons licence, unless indicated otherwise in a credit line to the material. If material is not included in the article's Creative Commons licence and your intended use is not permitted by statutory regulation or exceeds the permitted use, you will need to obtain permission directly from the copyright holder. To view a copy of this licence, visit http:// creativecommons.org/licenses/by-nc/4.0/.

\section{REFERENCES}

1. Thompson AC, Ang Li A, Asrani S. Agreement between trend-based and qualitative analysis of the retinal nerve fiber layer thickness for glaucoma progression on spectral-domain optical coherence tomography. Ophthalmol Ther. 2021;10(3):629-42.

2. Hwang YH, Kim YY, Kim HK, Sohn YH. Effect of peripapillary retinoschisis on retinal nerve fibre layer thickness measurement in glaucomatous eyes. $\mathrm{Br} \mathrm{J}$ Ophthalmol. 2014;98(5):669-74. 